\title{
A new approach to dreams in psychotherapy: Phenomenological dream-self model
}

\author{
Hayrettin Kara', Gökhan Özcan²
}

1 Istanbul Medipol University, Istanbul, Turkey

${ }_{2}^{2}$ Marmara University, Istanbul, Turkey

\begin{abstract}
Whether it is in traditional or modern context, dreams have a special place in both psychology and psychotherapy studies. 'The Traditional Interpretive Dream Approach' model, which we had come across its first remains in Mesopotamia and is also the inspiration for psychoanalysis, is based on the interpretation of the symbols in the dream with the principle of reaching the hidden meaning. However, what is done with this interpretation is to move away frodm the phenomenal subjective reality of the client. Our psychotherapy practice has forced us to see this fact in time: Dreams are also experiences just like the waking experiences and a phenomenal self has its place in the center of these experiences as it has in the waking ones. We modeled the dream studies in which we take dream self in the center and we called this model as 'Phenomenological Dream Self Model '(PDSM). The PDSM proposes a self-centered view and takes its theoretical background from its deepened practice. This practice also brings PDSM closer to the phenomenological view, in principle not based on the unconsciousness but on the consciousness of the dream self. There are four stages of PDSM. In the first stage the dream self-experience and in the second stage the waking self- experience are examined. These two are compared in the third stage and in the fourth stage, the associations related to dream are examined on the basis of the phenomenology of the dream self.
\end{abstract}

Keywords: phenomenological dream self-model, dream works, psychotherapy, self

\section{Introduction}

'Psychology is the science of mental life and its phenomena'(James, 1980). The subject of psychology is the mental life and conventionally the history of psychology is as old as the history of humanity. But in the modern sense, it has had a history for a hundred and thirty years. As Ebbinghaus (1908) said, 'Psychology has a long past but only a short history'. For psychotherapies, we can say the similar. We can generally accept any verbal and behavioral effort that addressing the problems in human's

*Correspondence: gokhan_0288@hotmail.com Huzur Mahallesi Abdullahazam Cad. No:35 Ümraniye/istanbul Received: 11 January 2019 Accepted: 26 May 2019

\section{Sleep and Hypnosis Journal homepage: http://www.sleepandhypnosis.org} ISSN:1302-1192 (Print) 2458-9101 (Online) mental life as a therapeutic attempt. In this respect, the history of psychotherapy is as old as the history of the first interpersonal relationship. Modern psychotherapies, which we call as psychotherapy today, have a history of approximately a hundred and twenty years (Schultz \& Schultz, 2016).

Whether it is in traditional or modern context, dreams have had a special place in both psychology and psychotherapy studies. The questions that we ask about the origin, meaning and function of the dreams today had been asked by our ancestors who lived thousands of years ago. From this point of view, we know that, from Ancient Egyptian Culture to Far Asian Culture, from Ancient Greek Culture to Islamic Culture, most of civilizations dreams have been interested in (Bulkeley, 2016). For example, one of the first written texts of humanity, the Epic of Gilgamesh contains an amazing dream narration and a dream interpretation. We can understand from these narrations what the people living in that period 
were thinking about the origin and the meaning of the dreams (Duralı, 2007). Additionally, in these narrations, we can psychotherapeutically see that dreams are decisive determiners in the perception of one's self, events and future. The 'Traditional Interpretive Dream Approach' which we have seen the first traces in Mesopotamia in 400o's BC and have been influential to all the civilizations in history, is going to be called as TIDA in this article. TIDA has three basic acknowledgements of the origin and structure of the dream; first claims that dreams originate out of personal consciousness. According to the second acknowledgement, dreams have hidden meanings beyond words, and these meanings are covered by symbols. The third acknowledgement is that the symbols in the dream must be interpreted to achieve the implicit meaning of the dream. These basic acceptances of TIDA have majorly continued also in dream theories in modern psychology. At the end of the 19th century, modern psychology has been shaped in an effort to be a natural science, by becoming independent from philosophy. Although there are many different schools under the umbrella of modern psychology, there are two effectively active schools from the beginning to the present: behaviorism and psychoanalysis (Hergenhahn \& Henley, 2009).

Behaviorism has seen dreams out of the content of psychology, claiming that there is no observable phenomenon. In contrast, psychoanalysis was born as science of dream. Sigmund Freud, the founder of psychoanalysis, bases his psychoanalysis on the dream approach both as a description of the human's mental structure and as a psychotherapeutic technique (Brenner, 1974). It is interesting to see that the basic acceptances of TIDA scientifically continue in Psychoanalytic Dream Theory (PDT). Just as TIDA, PDT also says that dreams come from the outside of personal consciousness, they have a hidden and implicit meaning which that is covered by symbols. These symbols must be interpreted in order to reach the hidden meaning. However, the PDT suggests completely distinctive theories about the structure of the unconscious, the content of the hidden meaning of the dream, and the techniques to reach it. According to PDT, dreams are the results of unconscious impulses. But unconscious impulses are not simply reproduced in sleep. These stimuli are changed by a series of processes and become undefined. Freud calls this assumed process 'dream process'. Therefore, the objects and events that show up in the dream are not what they are but those that substitute each other. According to PDT, these hidden dream thoughts can only be reached by operating the dream process backwards. The process of operating the dream process backwards is called dream interpretation (Freud, 1909). In modern psychology, Jung is the second important dream theorist after Freud. Although Jung differs from Freud about the semantic content of dreams and the techniques used to reach this meaning, he maintains formal assumptions of TIDA just like Freud (Bennet, 1995). Now we can show TIDA's basic assumptions and what they refer to in the PDT through a short dream in the Gilgamesh Epic.

'...And Then they both lay down to sleep. Gilgamesh had a dream and awakened Enkidu and told:

'... I had such a dream,

I've seen horrible things like nightmares,

I had a wild bull in the mountains.

Until the sky becomes invisible,

She freaked out and shouted.

I lost my strength, I was shocked,

Ifell on my knee.

Someone refilled me with the water from the waterskin and sobered me. "

After listening, Enkidu commented on his friend's dream:

'Your dream is good my friend,

The way we are on to,

Is not a wild bull.

The wild bull that you see is guard Shamash" "

(Epic of Gilgamesh).

Enkidu approaches and interprets his friend's dream according to TIDA's basic assumptions. The method of approaching the dream of two great dream theorists of modern psychology, Freud and Jung, would not be different from Enkidu's method. Both Freud and Jung would ask themselves the same question, just like Enkidu: "What does this bull in the dream symbolize?" It is essential to realize that the question is the same. Because the form of the question points out the method and its vision of self-consciousness.

In their interpretations, these three interpreters are basically based on the same assumption that the dreams are the symbolic narration of an unconscious 
reality. The difference is in the meaning that they refer to these symbols. For example, we know that Freud considers all dream appearances as symbolic distortions of unconscious sexual impulses (Freud, 1899). Therefore, it would not be surprising that he would say the raging bull in Gilgamesh's dream refers to his sexual desires for Enkidu. While following the same interpretive approach, Jung (1964) would say that the bull in Gilgamesh's dream is the equivalent of the archetypal monster image.

These assumptions have majorly determined the aspect of dream work in modern psychotherapies. These assumptions are remarkable since they give the opportunity to the therapists to interpret every dream according to their theoretical beliefs. However, what is done with these interpretations is to move away from the phenomenal subjective reality of the client. These assumptions have caused the dream approaches in modern psychology to have a completely speculative, mysterious, contradictory structure. Hence, this causes therapists, particularly young therapists, to avoid working on dreams in their psychotherapy practices (Yalom, 2002). In time, the problems of these assumptions have begun to be noticed and modern psychotherapists have proposed new approaches to overcome these problems (Fosshage, 2007; Hartmann, 2010; Hill and Rochlen, 2004). Although they have very different starting points, the common feature of these new approaches is to focusing more on the phenomenological structure of the dream, which is a positive development. However, in these approaches, dreams are still tried to be explained partly through the concept of unconscious.

Our practice of psychotherapy has forced us to see this fact in the course of time: dreams are like a life of wakefulness and in the center of this life there is a phenomenal self as well as wakefulness (Kara \& Selvi, 2017). This vision has led to a radical change in both our theoretical approach and practice related to dreams. When we intended to name and construct the visions and awareness that emerged from our experience, we realized that phenomenological philosophy was very much in line with our experiences. We did not initially examine phenomenological idea tradition and transfer this idea to dream study. Contrarily, we met phenomenological idea when we wanted to place our awareness emerging from our experiences to a context. We modeled our dream study by taking the dream self to the center and we called that the "Phenomenological Dream Self Model" (PDSM). Now we want to share what we mean by the dream self in the center of this model.

\section{Experience, self and dream self}

No doubt that our experience in our everyday life is our "own experience". In our waking experiences we are 'ourselves' in sense of self. In spite of this clearance of our awakening experiences, we are confused about dreams. Dreams first appear to us as completely different, unclear or mysterious phenomena from our waking experiences. It can be considered that both modern and traditional idea say that the dreams are originated from the unconscious as an attempt to ease the confusion by defining them. However, this does not really reduce confusion, but lead us away from the phenomenal reality of dreams. Reasons related to this can be listed as the unconscious attribution implies that dreams do not belong to us, or we are not ourselves in dreams. Then we tend to see dreams as a batch of images, or a bunch of reflections enclosed in a cellar. In our opinion, one of the most important misconceptions of modern psychology is the idea that dreams cannot be explained without the concept of unconscious. It is a typical example of this delusion that Jung (1953) said that dreams would only be a "ludus natura" (nature's excrement) without the unconscious. However, dreams are our own experiences, just like our waking experiences. As we are ourselves in our awakening experiences, we are also ourselves in our dream experiences. The way to understand that dreams are also our experiences is relied on to understanding that there is also a self in dreams. In an article earlier, we have suggested that the basic phenomenological qualities of the self in the awakening life are to be in a moment, to be in a place, to be in intentionality, to be in perceptions, and to be in sensuality (Kara \& Selvi, 2017). Then the question we need to answer is whether there is a self in dreams or not, if so, is the basic phenomenological qualities of this self-resemble that of the waking self or not? A phenomenological work on dreams will show us that there is an accessible self through the consciousness as well as the waking self. This dream self is like the waking self, it is at a "moment", in a "place", in "perception", and in "emotion". This dream self is always in an intentionality for an object just like the waking self. Approaching dreams through this phenomenal self can contribute to a better understanding of consciousness and 
subjectivity. More importantly comprehending dreams through the phenomenological self makes it possible to work more effectively, more easily, with dreams in psychotherapy.

If dreams are the experiences of a self, the most reliable way to understand these experiences is to define them as the way they are. In our perspective, the importance of phenomenology is that it gives a method for describing these experiences. In this context, now we want to summarize phenomenological theory and the psychological references of it.

\section{Phenomenology, phenomenological psychology psychotherapy and phenomenological dream works}

Phenomenology is a tradition of thought initiated by E. Husserl, the student of F. Brentano, a descriptive psychologist. As opposed to the types of research that go beyond our experience, phenomenology is a type of research that aims to describe the phenomenon given directly to our experiences and to return to things themselves (Husserl, 1907).

Although the phenomenology tradition is subdivided into sub-methodologies, there are some essential premises regardless of the type. A phenomenological study, basically, treats human experience as a matter all by itself; focuses on explanations and relationships rather than interpretation and causation; It deals with the way in which meaning is revealed in experience; it is not based on assumptions and theoretical speculations, but on the phenomenon; it is not grounded on subject-object distinction, but the consciousness and intention of the subject (Langridge, 2007).

As with any philosophical or psychological theory, phenomenology also has some basic principles and methods. First, it would not be wrong to say that the concept of 'intentionality' is at the heart of phenomenology. In a phenomenological study, the internal and external distinction is ignored; the subject is rather considered as in a close embrace to world, while the subject's intentionality to an idea, object and person is taken into account (Lyotard, 1954). One's intentionality is handled by a method called 'epoché' (bracket). Epoché is an effort to enable the researcher to suspend and neutralize all the dogmatic, theoretical assumptions and then to consider the expressions of experience as they are (Gallagher \& Zahavi,
2008; Spinelli, 2005; Zahavi, 2003). The aim is to free the researcher from dogmatism and provide awareness of the cognitive, meaning-giving aspect of experience (Creswell, 2013; Moustakas, 1994).

Phenomenology was born as a philosophical discipline, and then influenced by experimental and therapeutic areas of psychology. Phenomenology, along with phenomenological psychology, has become a qualitative research type that aims to reveal the psychological aspect of human experience in a manner consistent with the views of Husserl (Giorgi, 1997).

Phenomenology is assessed in two categories as descriptive and hermeneutic methodology with its use in psychology. The descriptive methodology follows the Husserl tradition and the hermeneutic methodology follows the Heidegger tradition (Finley, 2011). Some of the key differences between the descriptive type and the hermeneutic type are as follows: The descriptive type does not go beyond the data presented to it. The descriptive researcher can see the same uncertainty as a hermeneutic researcher, however to clarify the data the descriptive researcher does not add a comment that is not obtained from that data. A hermeneutic explanation often endeavors for a complete interpretation; a descriptive explanation can be shortcoming (Giorgi, 2009). Existential philosophy / psychotherapy movement has been highly influential in the integration of phenomenology into psychotherapy theory and practice. The Danish philosopher Kierkegaard had influenced Heidegger and Husserl, the German philosopher Heidegger had developed Husserl's phenomenology in his own unique way, a Swiss psychiatrist Ludwig Binswanger and Boss had transformed Heidegger's phenomenology into the existential-phenomenological paradigm of psychology and transferred it to psychotherapy. The specific aspect of phenomenological psychotherapy is that; while working on an experience, it excludes pre-acceptances and theories (such as the unconscious acceptance of psychoanalysis), reveals how individuals perceive their lives by describing and brings them to consciousness. Nevertheless, it is difficult to use a pure Husserlian phenomenology in clinical psychology and psychotherapy; since the clinicians' necessity of continuous relation and interaction with other people, makes it difficult to distinguish between phenomenological psychotherapy and existential psychotherapy (Moreira, 2011, 2009; Owen, 2006, 2007, 
2015).

Phenomenological psychotherapy is inspired by the theoretical infrastructure of phenomenology, which is the discipline of philosophy. First, the 'intentionality' of the client is very important in phenomenological psychotherapy. Intentionality is the intention of the client towards objects in the living self that remain constant while in flow of consciousness. Experience is at the core of intentionality. Experience is basically a feeling; but this is not just sensation. Feeling means that the clients feel that they are perceiving and thinking, it refers to a more sophisticated condition beyond the everyday use (Kara, 2018).

Second, the motor of the process in psychotherapy is the description. Meaning arises as a result of this description, which leads to the development of new meanings and understandings. Finally, phenomenological reduction in psychotherapy implies that the psychotherapist should bracket (epoché) his/her own experiences, assumptions, psychopathology and theoretical summation in his/ her relationship with the client, and he/she should reveal some of the themes at the level of consciousness of the relationship the client establishes with the world. Phenomenological intention in psychotherapy, as seen, builds the minimum possibilities of establishing a therapeutic relationship with the client. The ability to communicate and collaborate in psychotherapy and mental health practices, including biological and neurological fields, without the phenomenological method that constitutes ground theory and practice will be weak (Owen, 2015).

Considering the course of the phenomenological dream studies in psychotherapy, there are many different types of phenomenological attitudes. In the most general sense, we can say that dream studies in psychotherapy have moved away from the unconscious-centered perspective and evolved into a phenomenological view. It is possible to see the first clues of this evolution even in the first period of psychoanalysis. For example, although C. G. Jung was strictly committed to unconscious concept, his emphasis on the importance of the visible content of the dream over time and his use of the amplification method instead of the free association are a movement towards phenomenology. The efforts of later therapists of psychoanalytic origin to look into the visible content of the dream and examine the self-situations in dreams have brought them closer to the phenomenological view. Again, it is a movement towards the phenomenological view that Gestalt therapists such as Fritz Perls and Erving and Miriam Polster attached importance to the phenomena seen in the dream; thought that each phenomenon is part of the personality of the dreamer and that these parts must be integrated (Hill \& Knox, 2010). Aside from all these developments, we can accept the Swiss psychiatrist Medard Boss as a pioneer of phenomenological dream work in psychotherapy. Boss denied the archetypal interpretations that Jung brought to dreams and gave importance to the actual awakening life and suggested not intrapsychic but rather an interactive study (Gendlin, 1977; Montenegro, 2015). Craig and Walsh (1993) continued to enrich the phenomenological dream view on an existential-phenomenological ground.

\section{Phenomenological dream self model}

The PDSM is a four-stage model. According to this model, in the first stage of the dream work, the life of the dream self is described in terms of feelings, intentions and behaviors without any interpretation. In the second stage, it is described that how would the waking self experience or behave in the situations similar to dream experiences. In the third stage, the dream and waking selves are compared over the descriptive or data in the first two stages. In the fourth stage, the possibilities of new and different meaning layers of the dream life are searched based on the description in the first stage and the life story of the client. The model requires the therapist stays on the phenomenological descriptive attitude in the first three stages. Before we go to the detailed description of these four stages, we want to talk about the preparation phase.

Before starting to work on a dream with PDSM, the therapist should listen to the client's assumptions and beliefs on dreams and transfer the basic assumptions of the model to the client. The purpose of this preparation phase is to provide a partly reconciliation related to dreams between the therapist and the client. The clients' views on dreams are distributed within a spectrum. At one end of the spectrum there is the idea that dreams are totally meaningless and absurd. At the other end, there is the belief that dreams are covered with symbols and they have a certain and specific meaning. This end also includes believing that the dreams tell about the future. Without criticizing our clients' views on dreams, we draw their 
attention to a clear truth about dreams. That clear truth is; dreams are experiences and in our dream experiences we are 'ourselves' as we are in our waking experiences.

Establishing this awareness is the precondition of the dream work. This awareness provides the clients provide an opportunity focus on themselves in their dreams instead of events and objects. Therapists working with the PDSM try different ways that are compatible with their personal style to create this awareness for their clients. However, some of the questions asked to clients through any dream work often shape this awareness faster. For example, 'we are now in a therapy session and we both know and feel ourselves as ourselves. So, in your dream did you feel yourself as you feel right now?'. Or, calling the client by his name and say 'in terms of being Ahmet, is there a difference between Ahmet I speak now and Ahmet in his dream? Clients often answer these questions like 'Yes, I was myself in my dream.' or 'There is no difference about being myself'. The ones who say there is a difference might say e.g. they are not in the same age or the same feature as they are, they have different family members or friends, or they behave in a manner they would never behave. We explain these clients what we mean is not these kinds of differences but it is whether their self-perception is the same or not. In this preparation phase, we agree with most of our clients that we are ourselves in our dreams despite the difference in form or content. We ask some clients, who we can not have a full reconciliation, to give the method some time and their thoughts might change by working with this model in time. After such reconciliation, a dream that the client brings to the session is worked on as four stages.

\section{Phase 1: Phenomenological description of the dream self experiences}

The purpose of this phase is to reveal the feelings, intentions, perceptions, thoughts and actions of the self in the center of the dream experiences with all the details that can be remembered. The basic principle is that 'everything that exists in dream life is revealed and clarified as much as possible and that nothing that is not in a dream life is added to the dream'. In order to do this, the client is asked to suspend waking self while telling the dream and to remain in the experiences of the dream self. Because, the dream is not what the waking self sees it, it is what the dream self experiences. In addition to suspending the waking self of the client, the therapist should also suspend all his thoughts, theories, beliefs about dreams, and never attempt to interpret the dream. If the dream is written, it is read by the client. If it is a sound record the client and the therapist listen together. Clients often record their dreams as events and objects, and this causes the feelings and the intentions of the dream self to be skipped in the records. Once listened, the therapist carefully investigates the feelings, thoughts, and intentions of the dream self from each stage of the dream from the very first scene. In such a careful investigation, many feelings, that exist in dream life, but are omitted in records, are revealed.

At the end of the first phase, we have the pure description of the dream experience as what it is. As seen, our work in this phase is very similar to the aim of 'back to things themselves' in phenomenology and the "epoche" method used to achieve this goal. This pure description of the dream experience that we obtained at the end of the first stage is the key to the whole dream work. As we mentioned before, the therapist tries to stay in a descriptive phenomenological attitude that does not involve interpretation at this stage. Before starting to next phases, even at the end of this simplifying work many clients realize that the dreams they think are absurd or meaningless become meaningful. This is something we expect since the absurdity, meaninglessness or symbolism are the judgments of waking self not the dream self's. When the waking self is suspended, the meaning of dream experiences often occurs spontaneously in pure description.

In the last chapter we will share a sample dream work with PDSF. However, in this section, we believe that explaining the stages through a short dream will make it easier for us to be understood.

A young female client who had problems about her relationship came to therapy and said that her husband had cheated on her and they were about to divorce. During her therapeutic process, dream works were carried out with PDSF regularly. A significant portion of the dream experiences of this client in the sessions were related to relationship problems. One of the short dreams of the client was as follows:

"We were walking down the street with my husband. Suddenly I saw the woman with whom my husband had an affair in the corner and realized that she was following us. I showed the woman to my husband. My husband said, 'I 
knew that already, never mind'. We kept walking.".

We divided this dream into three scenes. First, we wanted her to focus on the moment she walked with her husband, and we asked all her thoughts and feelings that she could remember. She said "While I was walking with my husband, everything was natural, I was quite happy. I had no anger or rage against my husband."

Second, we asked her to describe her experience at the moment she saw the other woman; "the moment I saw her I felt terrible that almost my heart would stop and I would suffocate." Third we asked all the experiential details she could recall about the moment she told her husband; 'I was angry when I said it. My husband said "Never mind, don't care. I knew that already". That meant he doesn't care. I felt he didn't want me to be sad, he loves me. My husband's reaction comforted me, and I felt I was in love with him. We kept walking." As seen, in the phenomenological study many feelings which are very important in terms of the relationship of the dream self of the client with her husband but not mentioned in the dream record, have been revealed.

\section{Phase 2: Describing the experiences of the waking self}

The purpose of this phase is to reveal how the waking self feels, perceives and behaves in a dream-like situations. For this, clients are asked to envision a dreamlike situation in their awakening life and to predict how they would feel and behave in that kind of situation. If the clients had already experienced dream-like situations in their awakening lives like in the dream, they are asked to describe these experiences.

In many dreams, it is easy to imagine a similar version of dream experience in waking experience. As known, waking experiences are framed by a three-dimensional space, a forward and flowing principle of time and causality. But dream experiences can easily extend beyond this frame. In this respect, it may be absurd or difficult for the client to envision some dreams at once in awakening experiences. However, since the PDSM focuses on the emotions and intentions of the dream self instead of the events and objects in the dream experience, working in the second phase with such dreams is not as difficult as it seems. In this respect, the above dream is one that is easily imaginable in the second phase. In this phase, the client told that she had experiences not exactly the same but similar. She explained an argument about a text message on her husband's phone they had as an example and how it made her feel. She said "When this comes to the fore, I always focus on to leave him, also my friends I talk about this continuously advise me to divorce." When she was asked to envision the dream experience in waking experience she said "While I am walking down the street, I would know that I am going to meet that woman and she is following us. I would also know that my husband knows about that. I would never have acted like a dream. I would shout angrily at my husband, insult him, and get away from there, I would be absolutely determined to divorce him".

Phase 3: Comparison of the dream and waking selves given in the first two phases according to the descriptive information/data

At the end of the first two phases, we would acquire descriptions of the feelings, intentions and behaviors of both the dream self and the waking self. In the third phase, these two self-states should be compared. Sometimes the intentions of the two selves coincide, and sometimes there is an obvious 'angle difference* between the two selves. Sometimes these two selves of experiences coincide completely in terms of intentions, behaviors and feelings. Especially when there is an angle difference, many clients internally make this comparison even if the therapist does not say anything about the comparison. This is an expected situation. Because, it is surprising and striking to see that people have different feelings and behaviors in similar situations. This angle difference can sometimes force the clients emotionally depending on the content of dreams. However, both experiences belong to the clients and it is very useful to study this difference in terms of discovering or reconstructing the basic intentions of the self. The purpose of the therapist working with the PDSM is not to tell the clients something new but to try to make them hear their own voice. In cases where the angle difference arises, the clients say something that they do not say to themselves or something they do not want to hear in their waking experience.

In the above-mentioned dream study, there was a significant angle difference between the waking self and the dream self of the client. Her waking self is angry, insecure, unsure about her husband, and desperate for the future of their relationship. However, the dream self is feels that she loves her husband, she is gentler, less 
reactive towards him and she is eager to walk with him despite the problems. This dream is a dream that says that the client should review her thoughts, decisions and attitudes in waking.

This one and other dream works led to a new awareness about the client. She thought it would be better to suspend the divorce despite the suggestions of her peer influence and over time she observed that relations with her husband gradually improved. We presented this brief example of the dream to explain how to study the phases. Otherwise this is not a cross-sectional transfer of a therapeutic process.

\section{Phase 4: Research of the possibilities of new and different meaning layers of dream experience based on the description of the first phase and the life story of the client}

This is the phase at which the model permits interpretation relatively. However, this interpretation must always be done without departing from the phenomenological structure of the dream experience.

For many dreams, the first three phases of PDSM are sufficient for therapeutic work. Studying the fourth phase becomes important especially in the dreams where metaphoric and symbolic elements are dominant. For us metaphors and symbols are not the means of hiding something; on the contrary they are the means of being able to reveal and explain. Then it would make sense to ask the client the following question: "What could this dream correspond to in your life?" In the center of this question, the client tries to understand and find out what the experiences, events and objects which are not meaningful clearly in his/her dream may express in his/her own life. It is possible for the therapist to have an interpretive phenomenological attitude at this phase. Thus, the fourth phase allows the therapist to interpret on this question axis about the dream. However, as previously emphasized, this interpretation should be made in any case based on the description in the first phase. For example, such a question does not appear to be necessary for the short dream we have quoted above. Because it is very clear that the dream is to relive the problems of the client's husband on a different level.

\section{A case study}

The reasons for seeking help of Mr. F a 21-year-old university student were disgust, senselessness, lack of purpose and unwillingness. He complained about interruptions of his sleep and waking up very tired because of the nightmares he has been having for a long time. He was clinically diagnosed with depression according to DSM criteria, and the clinician stated that pharmacological treatment was the most appropriate option with a therapeutic work. Mr. F said that he did not want to take a medication, but he was eager for a therapy that included dream work. Mr. F came to every session with many dream records, and a considerable part of the sessions were devoted to dream work with the PDSM. Now one of the last dream works with this young client will be conveyed. The dream record that Mr. F shared by reading was like this:

"In my dream, I was on a platform on the sea. The platform was built for touristic reasons. These platforms were connected to the ground of 3-4 meters depth with chains. There were pits leading down near the places where each chain connected. The tourists were having fun by throwing the snakes at the bottom of the sea into these pits by holding them from their tails. I found myself in the water in a minute. On my right side, the snakes were waiting down there. On my left side there was a big fish that was poisonous in black and white at the bottom of the water and resembling a moray-eel that terrified me. I was very close to the snakes and scared. Then I saw the lying snakes on the ground turning towards me and slowly coming towards me. I started to swim to the left to escape from the snakes to the platform. However, I was also trying not to get too far left because I was terrified of the moray eel there. As I swam to the left, looking at the snakes (swimming to the left towards the right) my fear increased and as my fear increased, the speed of the snakes was increasing. The moment I turned left to see if I was too close to the moray-eel fish, it jumped on my face. I woke up screaming."

Before moving on to the first phase of the dream work with PDSM, it is useful for the therapist to ask the client about his first thoughts and feelings about his dream after waking up.

Therapist: What were your first thoughts and feelings about the dream when you woke up? Did the dream mean anything?

Mr. F: It did not seem to have so much meaning to me, but the sense of terror was intense. After I woke up, I had 
the feel of creeps for a while.

(In the first stage, the PDSM asks us to reveal the phenomenological structure of the dream experience 'as it is'. The therapist determines the questions for this purpose.)

Therapist: Please stay in your dream; stay in there and in that moment. You find yourself on a platform in the sea, and a little way off you can see tourists having fun with the snakes. How did you feel there and on that moment? Please tell me all the details you can recall.

Mr. F: I did not know how I got there. I had no idea why I was there, but I was not happy to be there at sea. I think I was thinking about getting out of the sea and move away. When I saw the snakes, I was feeling uneasy, but it was not much. I was a little bit surprised that the tourists were having fun with the snakes and I knew that I could not do that and I did not want to do it neither.

Therapist: Other people are having fun with snakes, but you do not think you can do it yourself. Did you have any idea of the reason for that at that moment?

Mr. F: Yes. It is interesting but I can remember clearly after you have just asked me. The snakes also knew that the tourists were not afraid of them, so they did not hurt them. But I was afraid, and the snakes knew that.

Therapist: How clear were these perceptions and cognitions in the dream?

Mr. F: Sometimes I feel like I realize and know something tentatively in my dreams. But this was not like that, for me it was quite clear.

Therapist: If we go back to your dream experience, you said you realized a big fish a little far from you while you were watching the tourists having fun with the snakes. What kind of mood were you at that moment?

Mr. F: When I saw that fish, I was terrified since it was a very dangerous and deadly fish.

Therapist: How did you know that the fish was so dangerous and deadly?

Mr. F: It was not exactly like a fish, but a monstrous fish; it had a big head and teeth. It had white and black stripes. It is being silence was creepy. I think its appearance made me think it was poisonous and deadly. But for that moment that was certain information for me, and I thought I had to keep away from it in all probability at that moment.

Therapist: So, let's look at what happened then. You see the snakes moving towards you and you're running away. What did you feel and think at this stage of your experience?

Mr. F: My fear increased a little when the snakes started to come towards me, but this fear was not much if I compare it to my fear of horrible fish. At that time, I had this awareness; snakes knew that I was afraid of them, so they were coming towards to me. While I was running away, I always had that poisonous, deadly fish in my mind, so, I was trying to determine my direction accordingly.

Therapist: You said the snakes were getting faster...

Mr. F: Yes, I felt like I was in a loop. As I was trying to be faster, the speed of arrival of snakes on me was increasing.

Therapist: Okay, now what about focusing on what you have been through at the last moment of your dream, your feelings and thoughts at that process?

Mr. F: As the snakes coming towards me faster, I was completely focused on running away. Suddenly I remembered the possibility of I might have ignored the poisonous fish and it might have approached to me. I turned my head to see if that was like that. The moment I turned my head, I came face to face with the horror. The monstrous fish was just there, and I woke up screaming at the moment it made a move towards my face to attack me.

The first phase of the dream work is the re-expression of the dream experience by bringing forward the elements of feeling and perception. At this phase, Mr. F actually remembered many perceptions and feelings that existed in his dream experience but were not included in the dream record. Highlighting this perception of thoughts and feelings, the therapist created and a re-description and re-narration of Mr. F's experience and shared this description.

" I'm in the sea, but I can't remember when and why I came there. I am not happy about being in the sea, and moreover I am anxious. A little far away, I see tourists holding snakes fearlessly and putting them into pits for having fun. I think that the snakes are dangerous for me and I fear them and stay away. In the meantime, I see an immobile fish that looks like a big, strange, moray eel standing away from me. I am terrified when I see it because I am like I know that the fish is very poisonous and deadly. Meanwhile, the snakes notice me and start to come towards me. I remember my thought about that moment very clearly. These snakes are coming towards me because they know I am afraid of them. Since they know other people aren't afraid of them, they let them play 
with themselves. But this awareness does not cool my fear down and I continue to run away. On the other hand, my mind is always on the deadly poisonous fish since I know it is so dangerous that it can't be comparable to the snakes. That is why I am trying to stay away from that poisonous fish while I am trying to run away from the snakes. At that moment I realize that as I was trying to be faster, the speed of snakes coming towards me was increasing. When I am in a hurry to run away, I suddenly realize that I forgot the poisonous fish for a moment, and I am in a deep suspicion of whether I am too close to that fish. The moment I turn my head around anxiously to understand that, the fish appears in front of my eyes. I'm so close that I feel like there's nothing I can do. The fish makes a move to attack my face and then I wake up screaming in great horror."

Therapist: I again told you what you have experienced. Is there anything in this narrative that is not in your dream?

Mr. F: No, there is not. Your narrative made me feel my dream even stronger.

As seen, we created a new narrative of experience without any interpretation and without adding anything to the dream that is not in the dream. This narrative also includes some awareness, knowledge and feelings of the dream self that is not included in the first record. For example, the thing that the snakes are not being merely scary, and it is his perception that transforms them into frightening and threatening objects. For example, the thing that the snakes accelerate as he accelerates to escape from the snakes, so he can't get free by escaping. For example, his facing the poisonous fish which is almost impossible for him to cope with just because he is escaping from snakes that he is afraid but can relatively cope with. Without studying the other phases, even in this first phase, the client majorly realized the awareness of the dream self and how this awareness was meaningful to him.

The model asks us to suspend the dream self in this second phase and to make it clear how the waking self will feel and behave in a similar experience.

Therapist: Have you had any experience similar to your dream before?

Mr. F: I go to the sea in the summer, but I have never had any experience about coming across snakes or poisonous fish. On the other hand, I go to the sea, but I have always been afraid of sea.

Therapist: What kind of fear is that?
Mr. F: The sea seems to me a dark obscurity. In this dark obscurity, I feel as if I am at risk. In this dark obscurity, I feel as if I am endangered. When I go to sea I do not swim far from the shore, even though I am a good swimmer.

Therapist: What do you think and feel about snakes?

Mr. F: I am too afraid of snakes. They are not cute animals for me.

Therapist: What about the fish?

Mr. F: Of course, I am not afraid of fish. But as I said, my fear in the dream is not the thing that its being a fish, it is about its being poisonous and deadly. I am also afraid of everything that is poisonous and deadly in my daily life.

Therapist: So how would you feel and behave if you are actually in a situation like your dream?

Mr. F: If I had a dream experience in my real life, my fear would be so much more than my dream experience. I would run again in panic.

The third phase involves the comparison of two selfstates or self-experiences in terms of intentions, thoughts, behaviors. In the previous example, there was a significant angle difference between the two self-states of the client. In this case, the client's two self-states are quite parallel in terms of their feelings and behaviors. If there was an angle difference, we would draw attention to this difference and ask him to think about it. The study of the angle differences is very useful for the person to recognize implicit, shaded areas. The lack of an angle difference shows that the intentions and the feelings that occur in the dream experience are settled in the self.

The fourth phase is more important, especially if there are dream experiences that are not made understandable in the first three phases of the dream. The predominant metaphoric and symbolic language in some dreams creates a feeling in the client and the therapist that there is a meaning that remains unrevealed. In such cases, the client is encouraged to make connections between the dream and waking experiences and the life story and to interpret the feelings, intentions and behaviors through these connections based on the phenomenological study of the first two phases. At this stage, the therapist may also suggest some interpretations, provided that the basic phenomenological principles are followed. Although Mr. F's dream carried symbolic elements, it became quite clear with the work in the first two phases. However, the study of the fourth phase, based on the descriptions in the first 
two phases, was helpful for better understanding of Mr. F's concerns. The therapist maintained the fourth stage study for this purpose.

Therapist: You said the sea would always be like an obscurity and open to danger. What can this obscurity and being open to danger refer to in your life?

Mr. F: It reminds me of the fears of my childhood I had in the dark, especially the ones in the evenings. As a child, I was so afraid of darkness as if everywhere was dark and something would come from any direction of the dark.

Therapist: Do you think that there is a connection of this kind of your fears with your fear of snakes?

Mr. F: The snakes are also uncontrollable for me, as if they are creatures that will suddenly emerge from any direction or from any hole.

Therapist: Can this uncertainty, obscurity and the feeling of being open to danger at any moment be connected to the sense of meaninglessness that you sometimes complain about?

Mr. F: I have never thought about it. But after you asked me, it seems like it can be.

Therapist: I wondered something about your dream experience again. In your dream, you fell into a danger you thought was almost impossible to cope with as you escaped from a danger you could relatively cope with. How about thinking what might your dream experience correspond to your real life?

Mr. F: I can not go to school. It is not about the fear though, it is about unwillingness. Maybe fear is a partly reason for that. If I force myself a little maybe I will go to classes. But as long as I don't go to school, a situation which I cannot handle like in my dream can occur. Now, when you have just asked, I felt this was a general feature of mine. Getting away from something but approaching the thing I ran away while getting away. I remembered a scene in Dostoevsky's novel 'The Idiot'. That scene seems to be telling my general attitude.

Therapist: I wonder a lot, could you tell me?

Mr. F: Mr. Mishkin would attend a ball the next day. There is a very precious vase on the corner of the big hall where the ball would take place, and Mishkin is very afraid that he would break that accidentally. When he attends the ball, with the fear, he tries to be on the other side of the hall away from that vase. He forgets that for a while, and he approaches to the vase without noticing and breaks the vase with a clumsy hand movement.
Therapist: You said that your dream was a meaningless nightmare in the beginning. What do you think now?

As seen, the fourth phase is a phase that allows associations and interpretations by continuing the connection with the phenomenological structure of the dream. For example, the associatively scene from the 'Idiot' which comes to Mr. F's mind is linked with the feeling, intention and behavior that are already in phenomenological structure of the dream. This is just one of the many dream works we have had with Mr. F. was experiencing more frequent and more frightening dreams during the first months of therapy. In the beginning, the general characteristic of the dreams he was experiencing was that the dream self was exposed to intense danger and threat, however he had no idea where and from whom the danger would come from. In time, the uncertainty in this sense diminished, and things that threatened him sometimes gained concrete form of an aggressive mafia group, an airplane crash, or, as in this dream, poisonous animals. Whatever the threat object was, the basic fear in all of his dream lives was the destruction of his physical being, the fear of death. Our aim in this article is to introduce you how to work on a single dream with four phases of PDSM. Otherwise, this exemplary dream work is not the transfer of a complete therapy work. For such a work, it is required to consider the previous dream works and to indicate the place of the transferred dream in the process; which is not our aim in this article.

\section{CONCLUSION}

PDT which is a modern follower of TIDAL, has prioritized the unconscious, the analysis of symbols and the latent content of the dream while it has given importance to the manifest content of dream and PDSM and has claimed that there is a thinking and feeling i.e. an experiencing phenomenal self in dreams, and has built its practice on this acceptance. This can be considered as an important theoretical break point in the history of dream theories.

With a four-stage process, the PDSM examines the client's experience of the dream self first and then the experience of waking self, with phenomenological sensitivity. In the third phase, the parallels and angle differences are interpreted by comparing two dream experiences and finally the associations about daily/past 
experiences are examined without departing from the dream self experience. The most important point that differentiates PDSM from the previous dream theory and models is that it does not separate the individual from the phenomenal experience in all four phases. PDSM work avoids imposing something that the clients have not said about their dreams by depending on some theories and

\section{References}

Bennet, E. A. (1995). What Jung really said?. Berlin: Schocken.

Brenner, C. (1974). An elementary textbook of psychoanalysis. New York: Anchor.

Bulkeley, K. (Ed.). (2016). Dreams: A reader on religious, cultural and psychological dimensions of dreaming. New York: Springer.

Craig, P. E., \& Walsh, S. J. (1993). Phenomenological challanges for the clinical use of dreams. G. M. V. Delaney (Ed.), New directions in dream interpretation (pp. 103-154). New York: SUNY.

Creswell, J. W. (2013). Qualitative inquiry \& research design, choosing among five approaches. California: Sage.

Dural, Ş. T. (Ed.). (2007). Epic of Gilgamesh. Istanbul: Dergah.

Ebbinghaus, H. (2009). Psychology: An elementary text book. New York: Cornell University Library.

Fosshage, J. L. (2007). The organizing functions of dreaming: Pivotal issues in understanding and working with dreams. International Forum of Psychoanalysis, 16(4), 213-221.

Freud, S. (2010). The interpretation of dreams: The complete and definitive text. (J. Strachey, Tr.) NY: Basic Books.

Freud, S. (1998). Five lectures on psycho-analyses. (J. Strachey, Tr.) New York: W.W. Norton \& Company.

Finley, L. (2011). Phenomenology for therapists: Researching the lived world. West Sussex: John Wiley \& Sons.

Gallagher, S., \& Zahavi, D. (2008). The phenomenological mind. NY: Routledge.

Gendlin, E. T. (1977). Phenomenological concept vs. phenomenological method: A critique of Medard Boss on dreams. Soundings: An Interdisciplinary Journal. 6o(3), 285-300.

Giorgi, A. (1997). The theory, practice, and evalution of the phenomenological method as a qualitative research procedure. Journal of Phenomenological Psychology, 28 (2), 235-260. doi: 10.1163/156916297Xo0103

Giorgi, A. (2009). The descriptive phenomenological method in psychology: A modified Husserlian approach. Pittsburgh: Duquesne University Press.

Hartmann, E. (2010). The nature and functions of dreaming. Oxford: Oxford University Press.

Hergenhahn, B. R., \& Henley, T. B. (2009). An introduction to the history of psychology. Belmont: Wadsworth.

Hill, C. E., \& Rochlen, A. B. (2004). The Hill cognitive-experiential model of dream interpretation. Cognitive Therapy and Dreams, 16(1), 161-178.

Hill, C. E., \& Knox, S. (2010). The use of dreams in modern psychotherapy. International Review of Neurobiology, 92, 291-317. doi: https://doi.org/10.1016/Soo74-7742(10)92013-8

Husserl, E. (2010). The idea of phenomenology. Dordrecht: Kluwer Academic. assumptions. Thus, the client's subjectivity is respected and kept safe from the risk of therapist's being directive.

In conclusion, we think that PDSM is a practical and effective dream model for clinicians who want to perform self-consciousness-based dream work in psychotherapy practices. In future studies, we aim for qualitative and quantitative researchs on the clinical benefits of PDSM.

James, W. (1983). The principles of psychology. Massachusetts: Harvard University Press.

Jung, C. G. (1964). Man and his symbols. Wiltshire: Laurel.

Jung, C. G. (2014). The collected works. New York: Routledge.

Kara, H. (2012). Workin with dreams in psychotherapy, a new approach. Başka Psychiatry Journal, 8, 169-192.

Kara, H. (2014). Dreams as an activity of a conscious mind and the therapeutic importance of the dreams. Dinlenen Ben Dream and Therapy Journal, 1(1), 4-11.

Kara, H. (2015). There is no sunshine but dreams are sufficiently bright. Dinlenen Ben Dream and Therapy Journal, 2(1), 2-6.

Kara, H. (2017). Challanges of creating theoretical framework for phenomenological-oriented therapy. Dinlenen Ben Dream and Therapy Journal, 5, 107-112.

Kara, H., \& Selvi, Y. (2017). Phenomenal self and dream self. Sleep and Hypnosis: A Journal of Clinical Neuroscience and Psychopathology, 19(4), 96-100.

Langridge, D. (2007). Phenomenological psychology: Theory, research and method. Essex: Pearson Education.

Lyotard, J. F. (1991). Phenomenology. Broadway: SUNY.

Montenegro, M. (2015). A comparison of Freudian and Bossian approaches to dreams. Existential Analysis. 26(2), 313-327.

Moreira, V. (2001). Beyond the person: Towards a mundane phenomenological psychotherapy. Santiago: Editorial Universidad de Santiago de Chile.

Moreira, V. (2009). Phenomenological-humanistic clinic: Studies in psychotherapy and critical psychopathology. Sa oPaulo: Annablume.

Moustakas, C. (1994). Phenomenological research methods. California: Sage.

Owen, I. R. (2006). Psychotherapy and phenomenology, on Freud, Husserl and Heidegger. NY: iUniverse.

Owen, I. R. (2007). Justfying on psychotherapy. New York: iUniverse

Owen, I. R. (2015). Phenomenology in action in psychotherapy, on pure psychology and its applications in psychotherapy and mental health care. Leeds: Springer.

Schultz S. E., \& Schultz, D. P. (2016). History of modern psychology. (Y. Aslay, Tr.) Istanbul: Kaknüs.

Spinelli, E. (2005). The interpreted world: An introduction to phenomenological psychology. London: Sage.

Turley, E. L., Monro, S., \& King, N. (2016). Doing it differently: Engaging interview participants with imaginative variation. Indo-Pacific Journal of Phenomenology, 16 (1-2), 153-162. doi: 10.1080/20797222.2016.1145873

Yalom, I. D. (2002). The gift of therapy. New York: Harper Collins. Zahavi, D. (2003). Husserl phenomenology. Stanford: SUNY. 